\title{
Candida glabrata colonizes but does not often disseminate from the mouse caecum
}

\author{
Correspondence \\ Carol L. Wells \\ wells002@umn.edu
}

Received 2 November 2006

Accepted 30 January 2007

\author{
Carol L. Wells, ${ }^{1,2}$ Mary-Alice Johnson, ${ }^{3}+$ Michelle J. Henry-Stanley ${ }^{1}$ \\ and Catherine M. Bendel ${ }^{3}$ \\ ${ }^{1}$ Department of Laboratory Medicine \& Pathology, University of Minnesota, Minneapolis, MN \\ 55455-0374, USA \\ ${ }^{2}$ Department of Surgery, University of Minnesota, Minneapolis, MN 55455-0374, USA \\ ${ }^{3}$ Department of Pediatrics, University of Minnesota, Minneapolis, MN 55455-0374, USA
}

\begin{abstract}
Candida glabrata is the second or third most frequent cause of candidaemia. The gastrointestinal tract is considered to be a major portal of entry for systemic candidiasis, but relatively few studies have investigated the pathogenesis of C. glabrata. Experiments were designed to clarify the ability of C. glabrata to disseminate from the mouse intestinal tract. Following oral inoculation, $C$. glabrata readily colonized the caeca [approx. $10^{7}$ cells (g caecum $)^{-1}$ ] of antibiotic-treated mice, but extraintestinal dissemination was not detected. Superimposing several mouse models of trauma and/or immunosuppression known to induce dissemination of Candida albicans and other intestinal microbes did not cause C. glabrata to disseminate often, although one exception was mice given high doses of dexamethasone for 4 days. These data support the hypothesis that the antibiotic-treated mouse intestine may be an epidemiological reservoir for C. glabrata and that this yeast tends to disseminate under specific clinical conditions.
\end{abstract}

\section{INTRODUCTION}

Systemic fungal infections are a major cause of morbidity and mortality in the critically ill, and a large proportion of infections occur in critical care units, including neonatal intensive care units (Rangel-Frausto et al., 1999). Candida species are the fourth leading cause of nosocomial bloodstream infections (Rangel-Frausto et al., 1999; Pappas et al., 2003; Wisplinghoff et al., 2004). Crude and attributable mortality are estimated at 57 and $38 \%$, respectively (Ruhnke, 2006). Risk factors for systemic candidiasis include prolonged antimicrobial therapy, glucocorticosteroids, peritoneal dialysis, haemodialysis, chemotherapy, radiation therapy, immunosuppression, mechanical ventilation, parenteral nutrition, high fungal colonization, neutropenia, bladder catheterization, intravascular catheters, complicated abdominal surgery, length of stay in the intensive care unit, and prematurity or very low birth weight (Charles et al., 2003; Pappas et al., 2003; Peres-Bota et al., 2004; Wisplinghoff et al., 2004). Candida albicans has historically accounted for the majority of Candida isolates, but non-albicans Candida are increasing in prevalence and Candida glabrata is now the second or third most frequently isolated Candida species (Rangel-Frausto et al., 1999; Pappas et al., 2003; Peres-Bota et al., 2004;

†Present address: Alaska Neonatology Assoc. Inc., 3340 Providence Drive \#366, Anchorage, AK 99508, USA.

Abbreviations: i.p., intraperitoneally; MLNs, mesenteric lymph nodes.
Wisplinghoff et al., 2004). Interestingly, of the more than 80 known Candida species, only C. glabrata exists solely as budding yeast and does not readily form hyphal elements, except under in vitro conditions of limiting nitrogen (Csank \& Haynes, 2000).

The gastrointestinal tract is believed to be the major colonizing habitat and a major source of systemic candidiasis (Cole et al., 1996; Blijlevens et al., 2002). Experimental studies provide direct evidence that $C$. albicans can disseminate from the intestinal lumen to extraintestinal sites. For example, extraintestinal dissemination of $C$. albicans has been reported in immunosuppressed gnotobiotic piglets (Andrutis et al., 2000) and in rodents given either broad-spectrum oral antibiotics (Kennedy \& Volz, 1985; Berg et al., 1993) or oral antibiotics coupled with immunosuppression (Ekenna \& Sherertz, 1987; Bendel et al., 2002, 2003). Using several strains of congenitally immunodeficient germ-free mice, Cantorna \& Balish (1990) reported some systemic spread after oral inoculation of $C$. albicans, although progressive systemic infection was seen only in mice with severe combined immunodeficiency. Using a severe model, Alexander et al. (1990) observed C. albicans within the intestinal epithelium and lamina propria of thermally injured guinea pigs following direct injection of yeast into the intestinal lumen. Few studies have focused on $C$. glabrata and relatively little is known about its pathogenesis (Fidel et al., 1999; Ruhnke, 2006). Our goal was to develop 
a mouse model to study the pathogenesis of systemic $C$. glabrata acquired via the intestinal route. The results were surprising and indicated that although $C$. glabrata readily colonized the mouse intestine, extraintestinal invasion did not often occur.

\section{METHODS}

Micro-organisms and mice. C. glabrata ATCC 15126 was obtained from the ATCC. Escherichia coli M21 is a streptomycin-resistant rodent isolate. For experiments, overnight cultures were washed and diluted in Hanks' balanced salts solution. Microbial concentrations were determined using a haemocytometer (C. glabrata) or by densitometry (Escherichia coli) and confirmed by quantitative culture on appropriate agar media. Female 18-22 g Swiss Webster mice (Harlan Sprague-Dawley) were allowed to acclimatize for 1 week before experiments. Male mice were not used because they tend to fight and wound each other, confounding the origin of systemic infection. Mice were killed by cervical dislocation. Experiments were performed according to the National Institutes of Health guidelines, and the University of Minnesota Institutional Animal Care and Use Committee approved all protocols.

Mouse model of systemic candidiasis. The classical model of intravenous injection of yeast cells into the tail vein (Spellberg et al., 2005) was used to assess the systemic virulence of this C. glabrata strain. Mice were injected with $0.1 \mathrm{ml}$ containing a defined number of yeast. In a preliminary experiment, $40 \%$ mortality was noted after injection of $10^{9} \mathrm{C}$. glabrata cells, with no mortality after injection of $10^{8}$ or $10^{7}$ cells. In subsequent experiments, mice were injected with $5 \times 10^{7}$ C. glabrata and randomly chosen to be sacrificed 1,8 and 15 days later for quantitative culture of kidney, liver and mesenteric lymph nodes (MLNs). Tissues were cultured on MacConkey agar, colistin nalidixic acid agar supplemented with $5 \%$ sheep red blood cells and Sabouraud's dextrose agar supplemented with gentamicin. Microbes were identified by standard techniques (Winn et al., 2006); rose-coloured colonies on CHROMagar Candida and lack of filamentation (standard tests for filamentation) confirmed that the recovered yeast was C. glabrata.

Mouse models of caecal colonization. To facilitate intestinal colonization with C. glabrata, mice were given bacitracin, streptomycin and gentamicin in their drinking water for 3 days prior to oral inoculation with $10^{7}$ C. glabrata cells (Wiesner et al., 2001; Bendel et al., 2003). This antibiotic regimen typically eliminates all detectable caecal bacteria. Unless otherwise stated, caeca and draining MLNs were cultured 3 days later and antibiotics were continued for the duration of the experiment. To induce extraintestinal dissemination, several models of trauma and/or immunosuppression were superimposed on this model of caecal colonization.

In one experiment, antibiotic-treated mice were randomized into hypoxia or normoxia groups. Immediately following oral inoculation of C. glabrata, mice in the hypoxia group were placed for $1 \mathrm{~h}$ in a chamber continuously flushed with $10 \%$ oxygen, $10 \%$ carbon dioxide and $80 \%$ nitrogen; mice were also placed in this environment for $1 \mathrm{~h}$ twice daily for the next 2 days and then sacrificed the following day. Control mice were placed in the chamber for the same time periods in room air. In another experiment, mice colonized with $C$. glabrata were injected intraperitoneally (i.p.) $16 \mathrm{~h}$ before sacrifice with $100 \mu \mathrm{g}$ Escherichia coli O111 : B4 LPS (List Biological Laboratories) suspended in $0.5 \mathrm{ml}$ sterile saline; control mice received sterile saline. In a subsequent experiment, LPS was combined with either hypoxia (described above) or surgical trauma. To induce surgical trauma, mice were anaesthetized with $500 \mu \mathrm{g}$ xylazine and
$2.5 \mathrm{mg}$ ketamine. The caecum and terminal ileum were exteriorized, gently manipulated for $1 \mathrm{~min}$ and the intestines returned to the peritoneal cavity. The incision was closed with clips and the mice were sacrificed the following day.

To assess the effect of immunosuppression, one group of mice was injected i.p. (at the time of oral inoculation with C. glabrata) with a monoclonal anti-granulocyte antibody, namely $150 \mu \mathrm{g}$ rat-anti-mouse Ly-6G (Gr-1) and Ly-6C (PharMingen) in $0.5 \mathrm{ml}$ Hanks' balanced salts solution; control mice received $150 \mu \mathrm{g}$ BSA. In the same experiment, another group of mice was injected i.p. with $0.5 \mathrm{ml}$ containing $2 \mathrm{mg}\left(100 \mathrm{mg} \mathrm{kg}^{-1}\right)$ dexamethasone sodium phosphate (Elkins-Sinn) twice daily for 2 days before sacrifice. (According to the product insert, the $\mathrm{LD}_{50}$ is $800 \mathrm{mg} \mathrm{kg}^{-1}$ in adult female mice.) In a subsequent experiment, mice were injected with dexamethasone for a longer period (4 days), and half of these mice also received $100 \mu \mathrm{g}$ LPS $16 \mathrm{~h}$ before sacrifice, whilst the other half received sterile saline. In the same experiment, another group of mice was injected i.p. with $0.5 \mathrm{ml}$ containing $5 \mathrm{mg}$ ( $250 \mathrm{mg} \mathrm{kg}^{-1}$ ) cyclophosphamide monohydrate (Sigma-Aldrich) 5 days before sacrifice (maximal bone marrow suppression; Mazur et al., 2002) and these mice also received $100 \mu \mathrm{g}$ LPS $16 \mathrm{~h}$ before sacrifice.

To assess extraintestinal dissemination of C. glabrata in mice with active bacterial dissemination, mice were divided into four groups: untreated mice orally inoculated with C. glabrata, mice pre-treated with oral antibiotics before oral inoculation with C. glabrata, mice pre-treated with oral antibiotics (bacitracin and streptomycin) before oral inoculation with $10^{9}$ streptomycin-resistant Escherichia coli M21 cells and mice pre-treated with oral antibiotics before oral inoculation with both C. glabrata and Escherichia coli. Mice were sacrificed 2 days later, as previous studies have shown that the majority of mice have translocating Escherichia coli at this time point in this model (Wells et al., 1987).

Statistical analysis. Fractional data were analysed by $\chi^{2}$ analysis with continuity correction. Microbial numbers were converted to $\log _{10}$ and analysed by an unpaired Mann-Whitney (two groups) or Kruskal-Wallis test followed by unpaired Mann-Whitney post hoc (more than two groups). Statistical significance was $P<0.05$.

\section{RESULTS AND DISCUSSION}

\section{Intravenous inoculation of C. glabrata in mice}

To assess systemic virulence of the C. glabrata strain used in this study, mice were injected intravenously with $5 \times 10^{7}$ C. glabrata. This yeast persisted in the kidney and liver with no significant decrease in fungal burden throughout the 15 day experiment. C. glabrata was recovered from the MLN complex, although the numbers declined over time (Table 1). Brieland et al. (2001) reported similar results with a clinical isolate of C. glabrata, i.e. persistence without significant net growth in a variety of mouse tissues for 21 days after intravenous inoculation. Thus the C. glabrata strain used in these studies had a systemic virulence similar to that of a clinical C. glabrata isolate.

\section{Oral inoculation of C. glabrata in antibiotic-treated mice}

In an initial experiment, antibiotic-treated mice were orally inoculated with C. glabrata and then placed under 
Table 1. Number of C. glabrata in the tissues of mice sacrificed 1, 8 and 15 days after intravenous inoculation of $5 \times 10^{7}$ C. glabrata

\begin{tabular}{|c|c|c|c|c|}
\hline \multirow{2}{*}{$\begin{array}{l}\text { Days after } \\
\text { inoculation }\end{array}$} & \multirow[t]{2}{*}{ No. of mice } & \multicolumn{3}{|c|}{ No. of $C$. glabrata in tissue (\% positive mice) ${ }^{\star}$} \\
\hline & & Kidney $\dagger$ & Liver $\dagger$ & MLN $\ddagger$ \\
\hline 1 & 10 & $4.2 \pm 0.6(90)$ & $5.0 \pm 0.7(90)$ & $1576 \pm 661(60)$ \\
\hline 8 & 10 & $4.7 \pm 0.6(70)$ & $4.2 \pm 0.5(90)$ & $792 \pm 703(60)$ \\
\hline 15 & $9 \$$ & $3.9 \pm 0.4(60)$ & $3.3 \pm 0.3(60)$ & $20 \pm 4 \|(44)$ \\
\hline
\end{tabular}

${ }^{\star}$ Lower limits were 2.5 and $2.1 \log _{10}$ C. glabrata cells (g kidney) ${ }^{-1}$ and (g liver) ${ }^{-1}$, respectively, and $10 C$. glabrata cells per MLN. Parentheses indicate the percentage of mice in which C. glabrata was recovered from tissue.

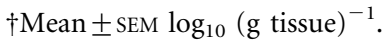

$\ddagger$ Mean \pm SEM per MLN.

§One death on day 3 .

IISignificantly decreased compared with day $1(P<0.01)$.

normoxic (room air) or hypoxic conditions. Hypoxia was used because mesenteric ischaemia compromises intestinal barrier function, which in turn has been reported to facilitate extraintestinal microbial dissemination (Magnotti \& Deitch, 2005). In both treatment groups, C. glabrata colonized the caecum at approximately $10^{7}$ cells

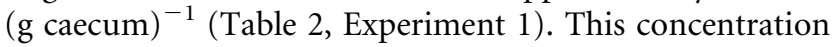
was probably close to the maximum obtainable, as, following oral inoculation with $C$. albicans, germ-free mice (with no competing microflora) become colonized with $10^{7}$ C. albicans cells ( $\mathrm{g}$ caecum) $)^{-1}$ (Helstrom \& Balish, 1979). (In all experiments in Table 2, C. glabrata was the only microbe recovered from mouse caeca.) In mice kept in room air, dissemination of C. glabrata to the draining MLNs was not detected and hypoxia had no significant effect on dissemination (Table 2, Experiment 1). As culture of MLNs is considered to be one of the more sensitive indicators of intestinal dissemination and as $C$. glabrata survived in the MLNs of intravenously injected mice (Table 1), failure to recover yeast from MLNs indicated an absence of extraintestinal dissemination. In a previous study using this model, similar hypoxic treatment facilitated extraintestinal dissemination of a mutant strain of C. albicans that does not readily form filaments and, like

Table 2. Effect of immunosuppression and/or trauma on caecal colonization and dissemination of C. glabrata to the MLNs of mice with antibiotic-induced caecal overgrowth

\begin{tabular}{|c|c|c|c|}
\hline Experiment & Treatment & $\begin{array}{l}\text { Mean } \pm \text { SEM } \log _{10} C . \text { glabrata } \\
\text { cells }(\mathrm{g} \text { caecum })^{-1}(n)\end{array}$ & $\begin{array}{l}\text { No. of mice with } C \text {. } \\
\text { glabrata in MLNs/total } \\
\text { no. of mice* }(\%)\end{array}$ \\
\hline \multirow[t]{2}{*}{1} & Normoxia & $6.9 \pm 0.1(8)$ & $0 / 24(0)$ \\
\hline & Hypoxia & $6.8 \pm 0.3(8)$ & $1 / 24(4)$ \\
\hline \multirow[t]{2}{*}{2} & i.p. saline & $6.6 \pm 0.2(8)$ & $0 / 24(0)$ \\
\hline & i.p. LPS & $8.1 \pm 0.1 \dagger(8)$ & $2 / 24(8)$ \\
\hline \multirow[t]{2}{*}{3} & i.p. LPS + surgery & $8.0 \pm 0.3(8)$ & $4 / 23 \ddagger(17)$ \\
\hline & i.p. LPS + hypoxia & $7.6 \pm 0.2(4)$ & $0 / 12(0)$ \\
\hline \multirow[t]{3}{*}{4} & i.p. BSA & $7.0 \pm 0.3(4)$ & $0 / 10(0)$ \\
\hline & i.p. anti-granulocyte serum & $7.1 \pm 0.3(4)$ & $0 / 10(0)$ \\
\hline & i.p. dexamethasone (2 days) & $7.6 \pm 0.2(4)$ & $0 / 10(0)$ \\
\hline \multirow[t]{3}{*}{5} & i.p. cyclophosphamide + i.p. LPS & $7.8 \pm 0.1(4)$ & $0 / 12(0)$ \\
\hline & Dexamethasone (4 days) & $7.8 \pm 0.1(4)$ & $7 / 12 \$(58)$ \\
\hline & i.p. dexamethasone (4 days) + i.p. LPS & $8.1 \pm 0.1(4)$ & $7 / 10 \$ 11(70)$ \\
\hline
\end{tabular}

${ }^{*}$ Number of C. glabrata recovered from MLNs varied from 10 to 4800 per MLN.

$\dagger$ Significantly increased compared with mice injected with saline $(P<0.01)$.

¥One death in 24 mice.

$\S$ Significantly increased compared with mice treated with cyclophosphamide plus LPS $(P<0.01)$.

IITwo deaths in 12 mice. 
C. glabrata, exists primarily in the yeast form (Kim et al., 2003). Thus we were surprised that hypoxia had no significant effect on dissemination of C. glabrata yeast cells.

Parenteral injection of rodents with LPS is often used to mimic septic shock and this treatment results in extraintestinal dissemination of normal enteric bacteria, such as Escherichia coli (Deitch et al., 1991). Antibiotic-treated mice colonized with caecal C. glabrata were given parenteral LPS or saline. Saline-treated mice appeared normal, whilst LPS-treated mice had characteristic lethargy, diarrhoea and ruffled fur, confirming the biological activity of LPS. Compared with saline-treated mice, LPS-treated mice had a nearly 32 -fold increase in the number of caecal C. glabrata cells, but dissemination to MLNs was not significantly increased (Table 2, Experiment 2). Similar results were obtained using a clinical isolate of C. glabrata (data not shown). This LPS-induced increase in the number of caecal C. glabrata was in contrast to a previous study using a similar mouse model where LPS did not increase caecal colonization of a wild-type strain of $C$. albicans that readily formed filaments in caecal contents; however, LPS was associated with increased caecal concentrations of a mutant $C$. albicans that was defective in filament formation and was seen in caecal contents solely in the yeast form (Henry-Stanley et al., 2003).

As systemic infection with C. glabrata is prevalent in postsurgical patients and surgical trauma (laparotomy) facilitates dissemination of enteric bacteria in rodents (Salman et al., 1992), antibiotic-treated mice colonized with caecal C. glabrata were subjected to laparotomy. As preliminary experiments indicated that simple laparotomy did not facilitate dissemination of caecal C. glabrata (data not shown), this surgical insult was combined with parenteral LPS. Dissemination of C. glabrata was not significantly increased in mice given LPS coupled with a surgical insult (Table 2, Experiment 3). In a companion treatment group, mice treated with parenteral LPS plus hypoxia also did not have noticeable dissemination of C. glabrata (Table 2, Experiment 3). These two double-hit models are clinically relevant because patients with systemic C. glabrata are often severely debilitated from multiple clinical insults (Fidel et al., 1999; Blot et al., 2001). In addition, there is substantial evidence that the biological responses of rodents to two-hit models (e.g. trauma plus sepsis) differ dramatically from responses to a single insult (Mishima et al., 1997; Dienstknecht et al., 2004; Suzuki et al., 2006). It was thus surprising that double-hit models involving LPS plus another insult (surgical trauma or hypoxia) did not induce dissemination of caecal C. glabrata.

The Gr-1 antigen is a specific marker for granulocytes (neutrophils, eosinophils and immature monocytes). Mice were injected with Gr-1 antiserum at a dose reported to cause profound depletion of blood and splenic granulocytes in mice for up to 5 days (Czuprynski et al., 1994), whilst another group of mice was given $100 \mathrm{mg}$ dexamethasone $\mathrm{kg}^{-1}$ twice daily for 2 days before sacrifice.
Neither treatment facilitated dissemination of caecal $C$. glabrata (Table 2, Experiment 4).

Although cyclophosphamide has been reported to augment extraintestinal dissemination of Enterococcus faecalis in mice with antibiotic-induced Enterococcus faecalis overgrowth (Miyazaki et al., 2001), dissemination of C. glabrata was not detected in mice given a similar dose of cyclophosphamide along with LPS i.p. (Table 2, Experiment 5). We reported previously that 4 days of dexamethasone treatment twice daily increased extraintestinal dissemination of $C$. albicans in mice with antibioticinduced caecal overgrowth (Bendel et al., 2002, 2003) and a similar result was noted with C. glabrata, although additional treatment with LPS did not have a significant additive effect (Table 2, Experiment 5). Thus extraintestinal dissemination of C. glabrata was facilitated by 4 days (but not 2 days) of high-dose dexamethasone treatment, but was not facilitated by cyclophosphamide or anti-granulocyte serum.

As caecal C. glabrata did not disseminate in the majority of the above clinically relevant models, we tested the ability of this yeast to disseminate in mice by active dissemination of caecal Escherichia coli. In antibiotic-treated mice orally inoculated with both Escherichia coli and C. glabrata, caecal Escherichia coli replicated to high numbers

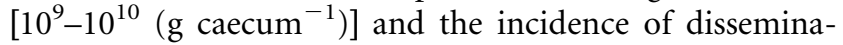
tion to the MLNs was high (Table 3). Although the high numbers of caecal Escherichia coli seemed to limit the numbers of caecal C. glabrata, this yeast was not recovered from the MLNs of mice with active dissemination of Escherichia coli.

Thus in several models of trauma and immunosuppression representing a variety of host defence alterations, $C$. glabrata did not often disseminate from the intestinal tract of mice harbouring C. glabrata as the only detectable caecal microbe. One exception was mice treated with high doses of dexamethasone, where C. glabrata was recovered from the MLNs of the majority of the mice. The reason for caecal C. glabrata dissemination following one form of immunosuppression but not another was beyond the scope of the present study, but experiments designed to clarify this issue might yield important information regarding the pathogenesis of C. glabrata.

There are several caveats to our general experimental design. First, mice were typically sacrificed 3 days after oral inoculation with C. glabrata and it is possible that longer time periods might yield different results. Secondly, systemic C. glabrata infections are often associated with old age and chronic disease (Weinberger et al., 2005) and our models used young adult mice given acute insults. Thus additional investigations are needed before these data can be extrapolated to humans. However, although the intestinal tract has been considered a primary portal of entry for systemic infection with Candida species, this paradigm may not apply to C. glabrata as frequently as it applies to other Candida species, including C. albicans. It 
Table 3. Caecal colonization and extraintestinal dissemination of Escherichia coli and C. glabrata in antibiotic-treated mice

\begin{tabular}{|c|c|c|c|c|c|}
\hline \multirow{2}{*}{$\begin{array}{l}\text { Oral antibiotics and/ } \\
\text { or oral microbial } \\
\text { inoculum }\end{array}$} & \multicolumn{3}{|c|}{$\begin{array}{c}\text { Mean } \pm \text { SEM } \log _{10} \text { microbes }(\mathrm{g} \text { caecum })^{-1} \\
(n=5 \text { per group })\end{array}$} & \multicolumn{2}{|c|}{$\begin{array}{l}\text { Percentage of mice with microbes in MLN } \\
\qquad(n=10 \text { per group })\end{array}$} \\
\hline & $\begin{array}{c}\text { Gram-negative } \\
\text { bacteria }\end{array}$ & $\begin{array}{l}\text { Gram-positive } \\
\text { bacteria }\end{array}$ & C. glabrata & E. coli $^{\star}$ & C. glabrata \\
\hline C. glabrata only & $5.4 \pm 0.3$ & $7.8 \pm 0.1$ & ND & 0 & 0 \\
\hline $\begin{array}{l}\text { Antibiotics plus } C \text {. } \\
\text { glabrata }\end{array}$ & $\mathrm{ND}$ & ND & $7.6 \pm 0.3$ & 0 & 0 \\
\hline Antibiotics plus E. coli & $9.2 \pm 0.1 \dagger$ & $3.6 \pm 0.1 \ddagger$ & $\mathrm{ND}$ & $80 \$$ & 0 \\
\hline $\begin{array}{l}\text { Antibiotics plus E. coli } \\
\text { and C. glabrata }\end{array}$ & $9.0 \pm 0.1 \dagger \ddagger$ & $3.9 \pm 0.5 \ddagger$ & $3.9 \pm 0.411$ & $60 \$$ & 0 \\
\hline
\end{tabular}

ND, None detected.

${ }^{*}$ Between 10 and 70 Escherichia coli per positive MLN.

$\dagger$ Only streptomycin-resistant Escherichia coli detected.

¥Only spore-forming Bacillus spp. detected.

$\$$ Significantly increased compared with mice given $C$. glabrata alone (with and without antibiotics) $(P \leqslant 0.01)$.

IISignificantly decreased compared with mice given antibiotics plus C. glabrata alone $(P<0.01)$.

would be challenging to design a study to confirm the clinical relevance of these data obtained from laboratory mice, but the results may be important. If the intestinal tract is not often a primary portal of entry for systemic infection with $C$. glabrata, more attention should be directed to defining the role of C. glabrata in sites such as the oral cavity, vagina, skin and indwelling catheters.

\section{ACKNOWLEDGEMENTS}

This work was supported by Public Health Service grant GM 059221 from the National Institutes of Health and by the March of Dimes Birth Defects Foundation grant \#6-FY04-53.

\section{REFERENCES}

Alexander, J. W., Boyce, S. T., Babcock, G. F., Gianotti, L., Peck, M. D., Dunn, D. L., Pyles, T., Childress, C. P. \& Ash, S. K. (1990). The process of microbial translocation. Ann Surg 212, 496-510.

Andrutis, K. A., Riggle, P. J., Kumamoto, C. A. \& Tzipori, S. (2000). Intestinal lesions associated with disseminated candidiasis in an experimental animal model. J Clin Microbiol 38, 2317-2323.

Bendel, C. M., Wiesner, S. M., Garni, R. M., Cebelinski, E. \& Wells, C. L. (2002). Cecal colonization and systemic spread of Candida albicans in mice treated with antibiotics and dexamethasone. Pediatr Res 51, 290-295.

Bendel, C. M., Hess, D. J., Garni, R. M., Henry-Stanley, M. \& Wells, C. L. (2003). Comparative virulence of Candida albicans yeast and filamentous forms in orally and intravenously inoculated mice. Crit Care Med 31, 501-507.

Berg, R., Bernasconi, P., Fowler, D. \& Gautreaux, M. (1993). Inhibition of Candida albicans translocation from the gastrointestinal tract of mice by oral administration of Saccharomyces boulardii. J Infect Dis 168, 1314-1318.

Blijlevens, N. M. A., Donnelly, J. P. \& De Pauw, B. E. (2002). Impaired gut function as risk factor for invasive candidiasis in neutropenic patients. Br J Haematol 117, 259-264.
Blot, S., Vandewoude, K., Hoste, E., Poelaert, J. \& Colardyn, F. (2001). Outcomes in critically ill patients with candidal fungaemia: Candida albicans vs. Candida glabrata. J Hosp Infect 47, 308-313.

Brieland, J., Essig, D., Jackson, C., Frank, D., Loebenberg, D., Menzel, F., Arnold, B., DiDomenico, B. \& Hare, R. (2001). Comparison of pathogenesis and host immune responses to Candida glabrata and Candida albicans in systemically infected immunocompetent mice. Infect Immun 69, 5046-5055.

Cantorna, M. T. \& Balish, E. (1990). Mucosal and systemic candidiasis in congenitally immunodeficient mice. Infect Immun 58, 1093-1100.

Charles, P. E., Doise, J. M., Quenot, J. P., Aube, H., Dalle, F., Chavanet, P., Nilesi, N., Aho, L. S., Portier, H. \& Blettery, B. (2003). Candidemia in critically ill patients: difference of outcome between medical and surgical patients. Intensive Care Med 29, 2162-2169.

Cole, G. T., Halawa, A. A. \& Anaissie, E. J. (1996). The role of the gastrointestinal tract in hematogenous candidiasis: from laboratory to the bedside. Clin Infect Dis 22 (Suppl. 2), S73-S88.

Csank, C. \& Haynes, K. (2000). Candida glabrata displays pseudohyphal growth. FEMS Microbiol Lett 189, 115-120.

Czuprynski, C. J., Brown, J. F., Maroushek, N., Wagner, R. D. \& Steinberg, H. (1994). Administration of anti-granulocyte mAb RB68C5 impairs the resistance of mice to Listeria monocytogenes infection. J Immunol 152, 1836-1846.

Deitch, E. A., Specian, R. D. \& Berg, R. D. (1991). Endotoxin-induced bacterial translocation and mucosal permeability: role of xanthine oxidase, complement activation, and macrophage products. Crit Care Med 19, 785-791.

Dienstknecht, T., Schwacha, M. G., Kang, S. C., Rue, L. W., Bland, K. I. \& Chaudry, I. H. (2004). Sex steroid-mediated regulation of macrophage/monocyte function in a two-hit model of traumahemorrhage and sepsis. Cytokine 25, 110-118.

Ekenna, O. \& Sherertz, R. J. (1987). Factors affecting colonization and dissemination of Candida albicans from the gastrointestinal tract of mice. Infect Immun 55, 1558-1563.

Fidel, P. L., Vazquez, J. A. \& Sobel, J. D. (1999). Candida glabrata: review of epidemiology, pathogenesis, and clinical disease with comparison to C. albicans. Clin Microbiol Rev 12, 80-96. 
Helstrom, P. B. \& Balish, E. (1979). Effect of oral tetracycline, the microbial flora, and the athymic state on gastrointestinal colonization and infection of $\mathrm{BALB} / \mathrm{c}$ mice with Candida albicans. Infect Immun 23, 764-774.

Henry-Stanley, M. J., Hess, D. J., Erickson, E. A., Garni, R. M. \& Wells, C. L. (2003). Effect of lipopolysaccharide on virulence of intestinal Candida albicans. J Surg Res 113, 42-49.

Kennedy, M. J. \& Volz, P. A. (1985). Ecology of Candida albicans gut colonization: inhibition of Candida adhesion, colonization, and dissemination from the gastrointestinal tract by bacterial antagonism. Infect Immun 49, 654-663.

Kim, A. S., Garni, R. M., Henry-Stanley, M. J., Bendel, C. M., Erlandsen, S. L. \& Wells, C. L. (2003). Hypoxia and extraintestinal dissemination of Candida albicans yeast forms. Shock 19, 257-262.

Magnotti, L. J. \& Deitch, E. A. (2005). Burns, bacterial translocation, gut barrier function, and failure. J Burn Care Rehab 26, 383-391.

Mazur, L., Augustynek, A., Daptata, A., Halicka, H. D. \& Bedner, E. (2002). Effects of WR-2721 and cyclophosphamide on the cell cycle phase specificity of apoptosis in mouse bone marrow. Anticancer Drugs 13, 751-758.

Mishima, S., Yukioka, T., Matsuda, H. \& Shimazaki, S. (1997). Mild hypertension and body burns synergistically increase bacterial translocation in rats consistent with a 'two-hit phenomenon'. $J$ Burn Care Rehabil 18, 22-26.

Miyazaki, S., Fujikawa, T., Kobayashi, I., Matsumoto, T., Tateda, K. \& Yamaguchi, K. (2001). Development of systemic bacteremia after oral inoculation of vancomycin-resistant enterococci in mice. $J$ Med Microbiol 50, 695-701.

Pappas, P. G., Rex, J. H., Lee, J., Hamill, R. J., Larsen, R. A., Powderly, W., Kauffman, C. A., Hyslop, N., Mangino, J. E. \& other authors (2003). A perspective observational study of candidemia: epidemiology, therapy, and influences on mortality in hospitalized adult and pediatric patients. Clin Infect Dis 37, 634-643.

Peres-Bota, D., Rodriguez-Villalobos, H., Dimopoulos, G., Melot, C. \& Vincent, J.-L. (2004). Potential risk factors for infection with Candida spp. in critically ill patients. Clin Microbiol Infect 10, 550-555.

Rangel-Frausto, M. S., Wiblin, T., Blumberg, H. M., Saiman, L., Patterson, J., Rinaldi, M., Pfaller, M., Edwards, J. E., Jr, Jarvis, W. \& other authors (1999). National epidemiology of mycoses survey (NEMIS): variations in rates of bloodstream infections due to Candida species in seven surgical intensive care units and six neonatal intensive care units. NEMIS Study Group. Clin Infect Dis 29, 253-258.

Ruhnke, M. (2006). Epidemiology of Candida albicans infections and role of non-Candida albicans yeasts. Curr Drug Targets 7, 495-504.

Salman, F. T., Buyruk, M. N. \& Celik, A. (1992). The effect of surgical trauma on the bacterial translocation from the gut. J Pediatr Surg 27, 802-804.

Spellberg, B., Ibrahim, A. S., Edwards, J. E., Jr \& Filler, S. G. (2005). Mice with disseminated candidiasis die of progressive sepsis. J Infect Dis 192, 336-343.

Suzuki, T., Shimizu, T., Szalay, L., Choudhry, M. A., Rue, L. W., Bland, K. I. \& Chaudry, I. H. (2006). Androstenediol ameliorates alterations in immune cells cytokine production capacity in a two-hit model of trauma-hemorrhage and sepsis. Cytokine 34, 76-84.

Weinberger, M., Leibovici, L., Perez, S., Samra, Z., Ostfeld, I., Levi, I., Bash, E., Turner, D., Goldschmied-Reouven, A. \& other authors (2005). Characteristics of candidemia with Candida albicans compared with non-albicans Candida species and predictors of mortality. J Hosp Infect 61, 146-154.

Wells, C. L., Maddaus, M. A., Reynolds, C. M., Jechorek, R. P. \& Simmons, R. L. (1987). Role of anaerobic flora in the translocation of aerobic and facultatively anaerobic intestinal bacteria. Infect Immun 55, 2689-2694.

Wiesner, S. M., Jechorek, R. P., Garni, R. M., Bendel, C. M. \& Wells, C. L. (2001). Gastrointestinal colonization of Candida albicans mutant strains in antibiotic-treated mice. Clin Diagn Lab Immunol 8, 192-195.

Winn, W., Allen, S., Janda, W., Koneman, E., Procop, G., Schreckenberger, P. \& Woods, G. (2006). Koneman's Color Atlas and Textbook of Diagnostic Microbiology, 6th edn. Philadelphia: Lippincott, Williams \& Wilkins.

Wisplinghoff, H., Bischoff, T., Tallent, S. M., Seifert, H., Wenzel, R. P. \& Edmond, M. B. (2004). Nosocomial blood stream infections in US hospitals: analysis of 24,179 cases from a prospective nationwide surveillance study. Clin Infect Dis 39, 309-317. 